\title{
Study of geostatistical inversion in the lithologic distribution and velocity modeling of thick igneous rock in the FY area, northern Tarim Basin, China
}

\author{
Yongzhong $\mathrm{Xu}^{\mathrm{a}}$, Haijun Yang ${ }^{\mathrm{b}}$, Gengxin Peng ${ }^{\mathrm{b}}$, Xingliang Deng ${ }^{\mathrm{b}}$, Qing Miao ${ }^{\mathrm{b}}$, Yiming Ma ${ }^{\mathrm{a}}$, \\ Juntao Liu ${ }^{\text {a,* }}$ \\ ${ }^{a}$ School of Resources and Geosciences, China University of Mining and Technology, Xuzhou 221116, China; \\ ${ }^{b}$ Institute of China Petroleum Tarim Oilfield Company, Korla 841000, China
}

\begin{abstract}
In the northern Tarim Basin, a large number of thick igneous rocks are encountered in the drilling process in the Permian, and lithology and velocity of them are violently varying, which has great influence on migration imaging of the "beaded". It is very important to conduct the fine lithology identification and high precision velocity modeling of the igneous rocks for the exploration and development of the reservoirs. A geostatistical inversion method to obtain igneous lithologic distribution pattern and velocity modeling in the FY area of northern Tarim Basin is introduced in this paper. The results show that the application of the geostatistical inversion method greatly improves the resolution of lithology identification, which helps us further understand the Permian igneous rocks distribution in FY area. By comparing the seismic facies classification maps of FY study area, it shows that the obtained velocity model can well reflect the lateral distribution of igneous rocks. At the same time, the velocity model can also reflect the variation of igneous velocity in details and has a high precision. The average velocity error of the wells participating in the inversion is less than $2 \%$, and the minimum average velocity error is $0.23 \%$. At last, the velocity model is applied to seismic data processing, the processing results indicate that it can help to improve seismic migration imaging. The study demonstrates that the geostatistical inversion method can provide a highprecision velocity model for formation pressure prediction, seismic data processing and interpretation, and guide the exploration and development of oil.
\end{abstract}

Keywords: Thick igneous rocks; Geostatistical inversion; Lithology distribution; Velocity modeling

\section{Introduction}

In northern Tarim Basin, there are widely distributed igneous rock. The lithology of igneous rocks changes violently in both vertical and horizontal directions. The velocity of different igneous rock varies greatly, and the high-precision velocity model is one of the cores of prestack depth migration. The unclear understanding of igneous lithology and velocity has a great influence on the exploration and development of oil. A lot of works have been carried out to solve the difficult problems of rock lithology identification and velocity modeling. BP neural network is utilized to identify igneous rock with poor reflection energy and poor continuity,

\footnotetext{
*liujuntao20082009@126.com, liujt@cumt.edu.cn
} 
which can provide a more reliable basis for the deployment of new wells(Zhang et al., 2003). Seismic attributes, rock physical characteristics, seismic inversion and seismic forward modeling are combined to the characteristics of igneous rock in the Tazhong area and better understanding about the igneous rock in the study area is obtained(Luo, 2006). In order to obtain the velocity characteristics of igneous rocks accurately, probabilistic neural network inversion and seismic multi-attribute analysis are used to establish the velocity field of Tabei in Xinjiang which is in conformity with the geological characteristics(Xie et al., 2015 ). A contrastive study of the method determining lithology and velocity of Permian igneous, such as constrained sparse spike inversion, artificial neural network inversion and logging multiparameter inversion, is carried out. The results show that the fast modeling based on constrained sparse pulse inversion is more suitable for velocity modeling(Cui et al., 2016). Ambient noise tomography is utilized to study the velocity structure of the basalt and sub-basalt and a more structurally complex and laterally heterogeneous crust are obtained(Sammarco et al., 2017). Seismic interpretation, artificial neural networks, and model-based inversion are adopted to study the seismic response of the igneous intrusions and lava flows(Naviset et al., 2017).

In the above works, conventional methods of wave impedance inversion and velocity modeling are used to study igneous rock. The common problem is that the vertical resolution is not enough to distinguish the thin interbed, which will result in inaccurate lithology and velocity prediction. The complex lithology of igneous rock with great thickness and velocity variation in the FY area can be broadly divided into three types: dacite, basalt and pyroclastic rocks. The seismic reflection characteristics of the dacite are as follows: the reflection energy is weak; The continuity of the seismic event is poor, and the amplitude varies greatly. Basalt has stronger reflection energy but thin thickness. The pyroclastic rocks are thick and its lithology is complex. All those characteristics make it difficult use conventional seismic inversion methods to finely identify the complex lithology of the igneous rock in FY area. Geostatistical inversion combines deterministic inversion with stochastic simulation can finely depict the thin interbed and improve the resolution of the lithologic inversion result (He, 2013; Shen et al., 2016; Zhang et al., 2016). A method based on geostatistical inversion of igneous rock is introduced to understand the lithology and velocity distribution pattern of the thick igneous rock in FY area more accurately, and obtain the high-precision velocity data of the Permian igneous rock to guide the work of oil exploration and development. 


\section{Methodology}

\subsection{Geostatistical inversion method}

The geostatistical inversion method combines the stochastic simulation with the seismic inversion, which is actually a process of optimizing the multiple simulation results on the basis of stochastic simulation and the understanding of geological data in work area(Bellatreche et al., 2017; Pereira et al., 2017; Sabeti et al., 2017; Tamaki et al., 2016; Wang and Wang, 2013). Bayes discriminant theory and Markov chain-Monte Carlo sampling algorithm are the two cores of geostatistical inversion. Bayes discriminant theory can combine with seismic, logging and geological prior information to obtain the posterior probability density function of lithologic body. The Bayes formula is expressed as:

$$
\mathrm{p}(X \mid H, E)=\frac{\mathrm{p}(X \mid H) \mathrm{p}(E \mid X)}{P(E \mid H)}
$$

where, $\mathrm{p}(X \mid H, E)$ is the posterior probability density function, $\mathrm{p}(X \mid H)$ is the prior distribution of the parameter $\mathrm{X}$ under the condition of hypothesis $\mathrm{H}, \mathrm{p}(E \mid X)$ is a likelihood function observed under known $\mathrm{X}$ conditions, $P(E \mid H)$ is the regular factor.

However, one lithology or lithofacies often corresponds to multiple attribute parameters. In practice, it is difficult to solve the posterior probability density distribution function while the Markov chain-Monte Carlo sampling algorithm provides a solution for its solution (Han et al.). The basic idea of the algorithm can be summarized as the following three points:

(1) Constructing a Markov chain and converging it to a stationary distribution $\pi(\mathrm{x})$;

(2) Generating a sample: Starting from a point $\mathrm{x}^{(0)}$ in a certain space $\Phi, \mathrm{n}$ is the total number of generated samples, sampling with the Markov chain in (1) and generating a point sequence: $\mathrm{x}^{(1)}, \mathrm{x}^{(2)}, \ldots, \mathrm{x}^{(\mathrm{n})}$;

(3) Monte Carlo integration. $m$ is the number of samples when the chain is smooth, the expection estimation of any function $f(\mathrm{x})$ is:

$$
\mathrm{E}[f(x)]=\frac{1}{n-m} \sum_{t=m+1}^{n} f\left(x^{(t)}\right)
$$

\subsection{Establishment of lithology curve}

Sensitive parameter analysis of different lithology of igneous rock is a prerequisite for geostatistical inversion. Through sensitivity analysis, the parameters which are sensitive to lithology of igneous are found, such as wave impedance, natural gamma, etc. They are used 
for classification of lithology, analysis of geostatistical parameters, and subsequent geostatistical inversion. Combined with geological data, the lithology of Permian igneous rock in the study area is divided into three categories: dacite, basalt and pyroclastic rock. Sensitivity analysis that the natural gamma curve is sensitive to igneous rock, and wave impedance is also an important parameter to distinguish igneous rock. Therefore, this two curves are selected as the sensitive curves of igneous rock in the study area, and the logging responses of different lithology is analyzed as shown in Table 1. The lithologic curves in FY area can be calculated by Table 1, which lays the foundation for geostatistical parameter analysis and inversion.

Table 1 Lithologic logging response characteristics of igneous in FY area of northern Tarim Basin

\begin{tabular}{lll}
\hline Igneous lithology & Natural gamma value $($ gAPI) & P-impedance value $\left(\mathbf{k g} / \mathbf{m}^{\wedge} \mathbf{3} * \mathbf{m} / \mathbf{s}\right)$ \\
\hline Dacite & $100-190$ & $>1.17 \mathrm{e}+07$ \\
Basalt & $30-60$ & $>1.17 \mathrm{e}+07$ \\
Pyroclastic rocks & $50-190$ & $6 \mathrm{e}+06 \sim 1.17 \mathrm{e}+07$ \\
\hline
\end{tabular}

\subsection{Constrained sparse spike inversion}

CSSI is a recursive inversion method based on convolution model, which respects the seismic data and transforms the seismic reflection information into wave impedance information, and obtains the spatial distribution rule of the formation physical parameters(Yang et al., 2011; Yongzhong et al., 2010). The CSSI method that identify the igneous lithology and establish the igneous velocity model can rapidly obtain the Permian igneous lithologic information in FY area, and it also can reflect the spatial distribution of igneous physical parameters on the whole.

Fig. 1 shows the inversion results of the Permian igneous rock in the FY area, which elementarily reflects the developmental law of igneous in the longitudinal direction. The igneous lithology in the upper Permian is dominated by dacite and basalt both with high impedance value, and the underlying igneous lithology is pyroclastic rocks with low wave impedance value. The inversion result is consistent with the law of geological recognition, and there is a relatively continuous pyroclastic rocks interlayer between dacite and basalt, which updates the distribution law of Permian igneous in FY area. However, due to the limitation of vertical resolution, more details can not be reflected, and geological inversion is utilized to further improve the vertical resolution of the inversion results. CSSI is an important part of geostatistical inversion. Well seismic calibration and time-depth transformation, fine geological model establishment, seismic wavelet extraction will be used into geostatistical inversion, and the absolute impedance of the deterministic inversion is used to obtain the horizontal variation function. 


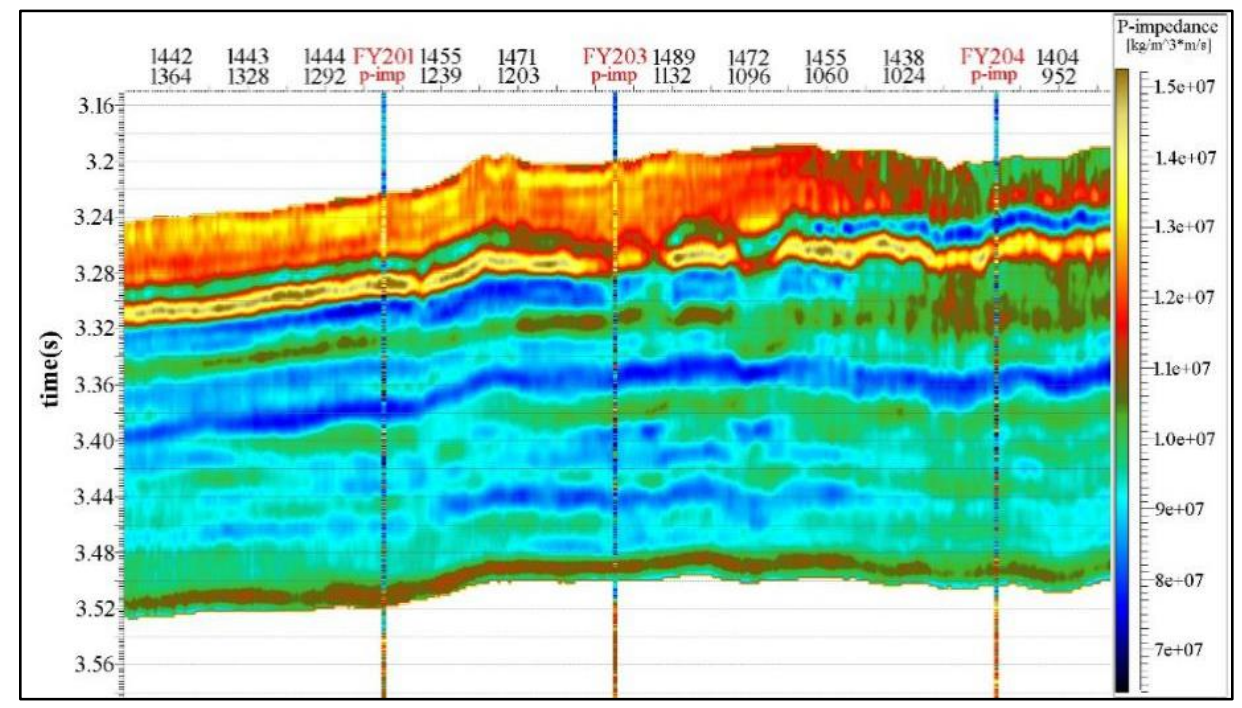

Fig. 1 Constrained Sparse Spike inversion section of cross-well FY201, FY203 and FY204

\subsection{Optimization of geostatistical parameters}

The geostatistical parameters mainly include probability density function (PDF) and variation function. The probability density function describes the possibility of a distribution of elastic parameters corresponding to a particular rock facies. The types of probability density function include Gauss type function, equal distribution function, uniform distribution function and logarithmic Gauss type function. The data shows that Gauss function can reflect the distribution of data sample point better as shown in Fig. 2. Therefore, Gauss function is used to analyze the logging impedance data of igneous rock of different lithology in FY research area. Figure 2 shows the wave impedance frequency distribution histogram and Gaussian transformation curve of the pyroclastic rocks in TT2 layer with an average value of $9.24 \times 10^{6}$ and a standard deviation of $8.62 \times 10^{5}$.

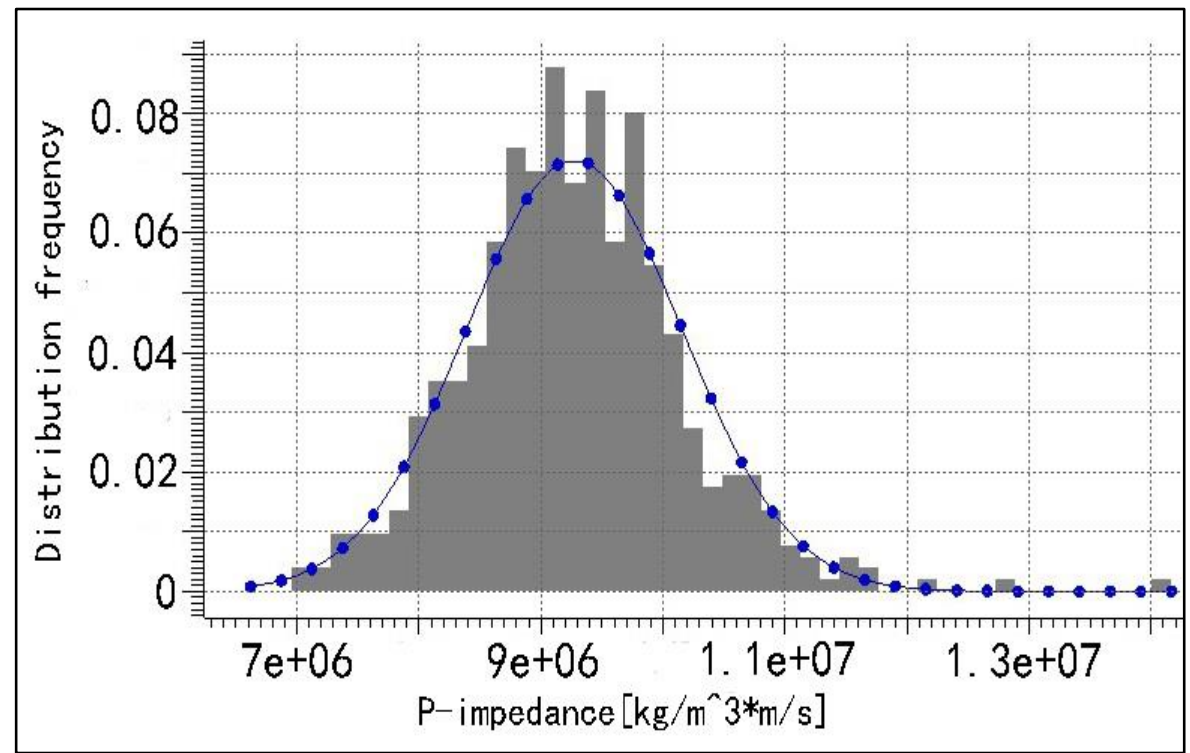

Fig. 2P-impedance gaussian transformation of pyroclastic rocks of TT2 layer in the FY work area 
The variation function describes the transverse and longitudinal structure and scale of the geological features, which measns the size of different lithofacies and its attributes in the spatial distribution pattern and the change scale. It is used to describe the spatial correlation of different lithofacies data. The variation function is defined as:

$$
r(h)=\frac{1}{2 N(h)} \sum_{i=1}^{N(h)}\left[z\left(u_{i}\right)-z\left(u_{i}+h\right)\right]^{2}
$$

where, $h$ is the lag distance, and $\mathrm{r}$ is the variation function value, $N(\mathrm{~h})$ is the number of distance $h$, and $z\left(u_{i}\right)$ is a regional variable.

Variable range is an important parameter of variation function, representing the maximum correlation distance in space(Goovaerts, 1994; Zhang et al., 2017; Zhi et al., 2015). The larger the range, the larger the correlation scale indicating the spatial distribution of the regional variables, the slower the change rate and the less random. Since the logging data has a high longitudinal resolution, the sample of logging data is used to calculate the vertical variation function, and the horizontal variation function is calculated from the seismic inversion body with higher lateral resolution. The scientific and accurate variation function can make the geostatistical inversion accurately reflect the spatial distribution characteristics of igneous in FY area. Fig. 3 shows the vertical variation function curve of the wave impedance of pyroclastic rocks of the Permian TT2 layer in FY area, and it can be seen that the variable range is small, which indicates that the pyroclastic rocks are thin and its lithology changes rapidly.

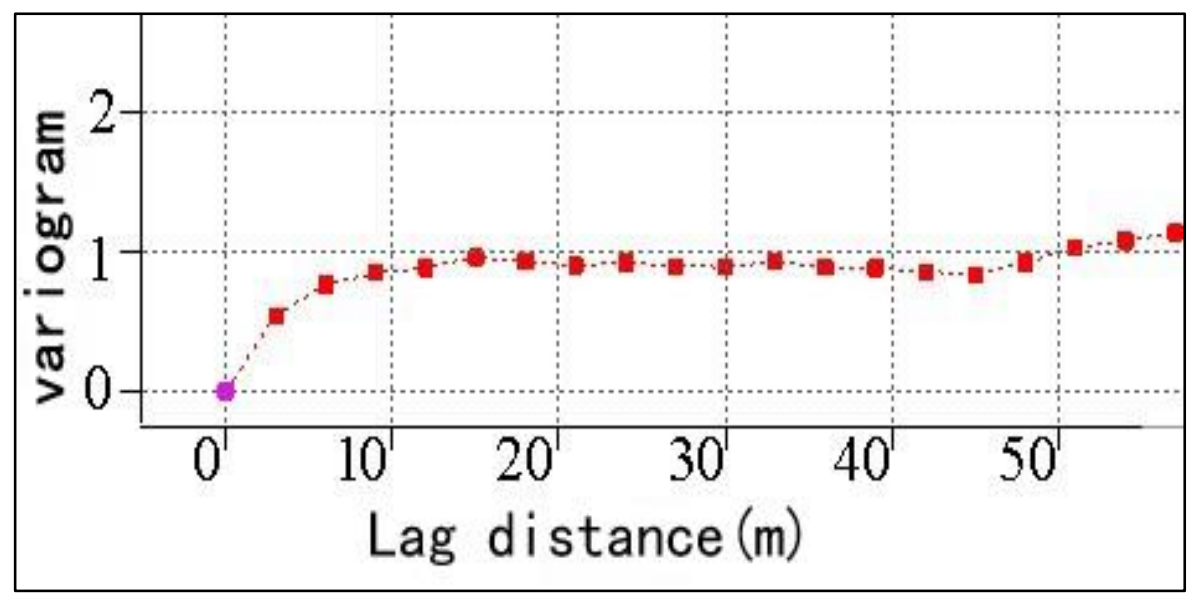

Fig. 3 P-impedance vertical variation function of pyroclastic rocks of TT2 layer in the FY work area

\subsection{Signal to noise ratio and quality control}

After analyzing the probability density function and variation function, the random simulation and geostatistical inversion can be carried out. However, in the inversion, it is necessary to determine the weight of the seismic data, that is, the signal to noise ratio(SNR), 
the range of which should be between $1-30 \mathrm{~dB}$. The higher the SNR, the smaller the residual. Fig.4 shows the SNR histogram of the CSSI results of the Permian igneous rock in FY area, and most of the SNR are centered between $10-25 \mathrm{~dB}$, which also reflects that the CSSI results of the Permian igneous rock in FY area matches well with the true seismic record. After several tests, the SNR was determined to be $18 \mathrm{~dB}$.

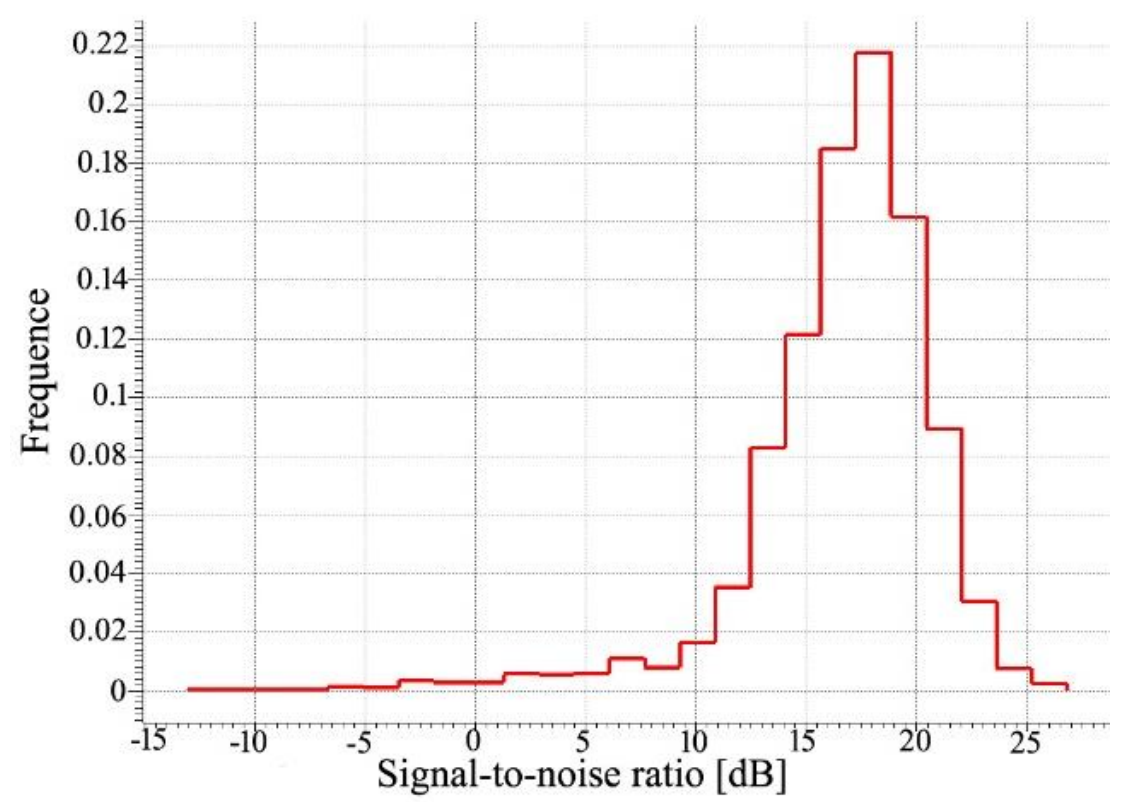

Fig. 4 SNR histogram of the CSSI results of the Permian igneous in FY area

In the process of geostatistical simulation and inversion, quality control is required to check the correctness of the inversion results(Dong et al., 2013). In the process of geostatistical simulation, the quality control content is mainly to observe the simulated profile and the CSSI profile. The distribution, scale, lithology ratio and connectivity of the rock obtained by the two methods should be basically identical without over-emphasizing the details. In the process of geostatistical inversion, in addition to comparing the consistency between geostatistical inversion prifile and CSSI profile. There is also a test method: well extracting test, which can be divided into two ways to check the result of inversion, one is to observe whether the inversion body around the well is consistent with the well lithologic curve in the inversion profile, the other is to compare the extracted geostatistical inversion wave impedance curve of the well point with the original wave impedance curve of the well to see if it is consistent.

\section{Case study}

\section{1. General geology and igneous characteristics of work area}

FY study area is located in southwestern slope of Lunnan low uplift, north tarim uplift. The area is near the Luntai uplift on the North, the northern depression on the South, the Yingmaili 
low uplift on the West and the Lunnan low uplift on the East. The total area for full fold of FY region is $588.2 \mathrm{~km}^{2}$. It has been drilled thick igneous rock with violently varying lithology and velocity in the both lateral and vertical direction, whose thickness is between $500 \mathrm{~m}-700 \mathrm{~m}$. There are 10 wells in FY area and all of them are drilled thick igneous. According to the types of rock structure, the rock types are divided into two major categories: volcanic lava and pyroclastic rocks. Volcanic lava is dominated by dacite and basalt, while pyroclastic rocks are dominated by tuff and tuffaceous sandstone and mudstone. According to the chemical type and mineral composition, the igneous rock are divided into three categories: basic igneous, neutral igneous and acidic igneous, but the distribution of neutral andesite are limited. The basic basalt and acidic dacite are mainly developed. Fig. 5 is a synthesis column map of FY201 wells in FY area. In the figure, the GR and acoustic logging responses, corresponding typical seismic sections and cuttings microsection of different igneous rock are displayed.

The two logging curves in igneous rock segment are more stable after entering the Permian, and they have a sudden change in the lower igneous rock segment. It shows that the acoustic logging curve is changed from low to high and then low, and the natural gamma value is changed from high to low. Then the two curves remain stable and the mutation occurs again in the pyroclastic rocks segment. According to the responses, the Permian in FY area can be divided into three sections: upper, middle and lower segments. In upper section, the GR values are high, and the lithology is dominated by acidic igneous. In middle section, the GR values are low, about 30-50API, and the lithology is dominated by basic igneous. The logging curves of the lower section vary greatly, while the lithology of igneous rocks varies greatly. By taking cuttings and identification of cuttings microsection by microscope, it is found that crystal fragments of acidic dacite at $4550 \mathrm{~m}$ are plagioclase, quartz, and oxidized amphibole. The basic basalt is found at $4610 \mathrm{~m}$ with intersertal and implicit structure. The matrix is microcrystalline plagioclase, pyroxene, magnetite and crystalline. In addiation, there is tuffaceous fine sandstone with calcite found in the crumbs at $4750 \mathrm{~m}$. 


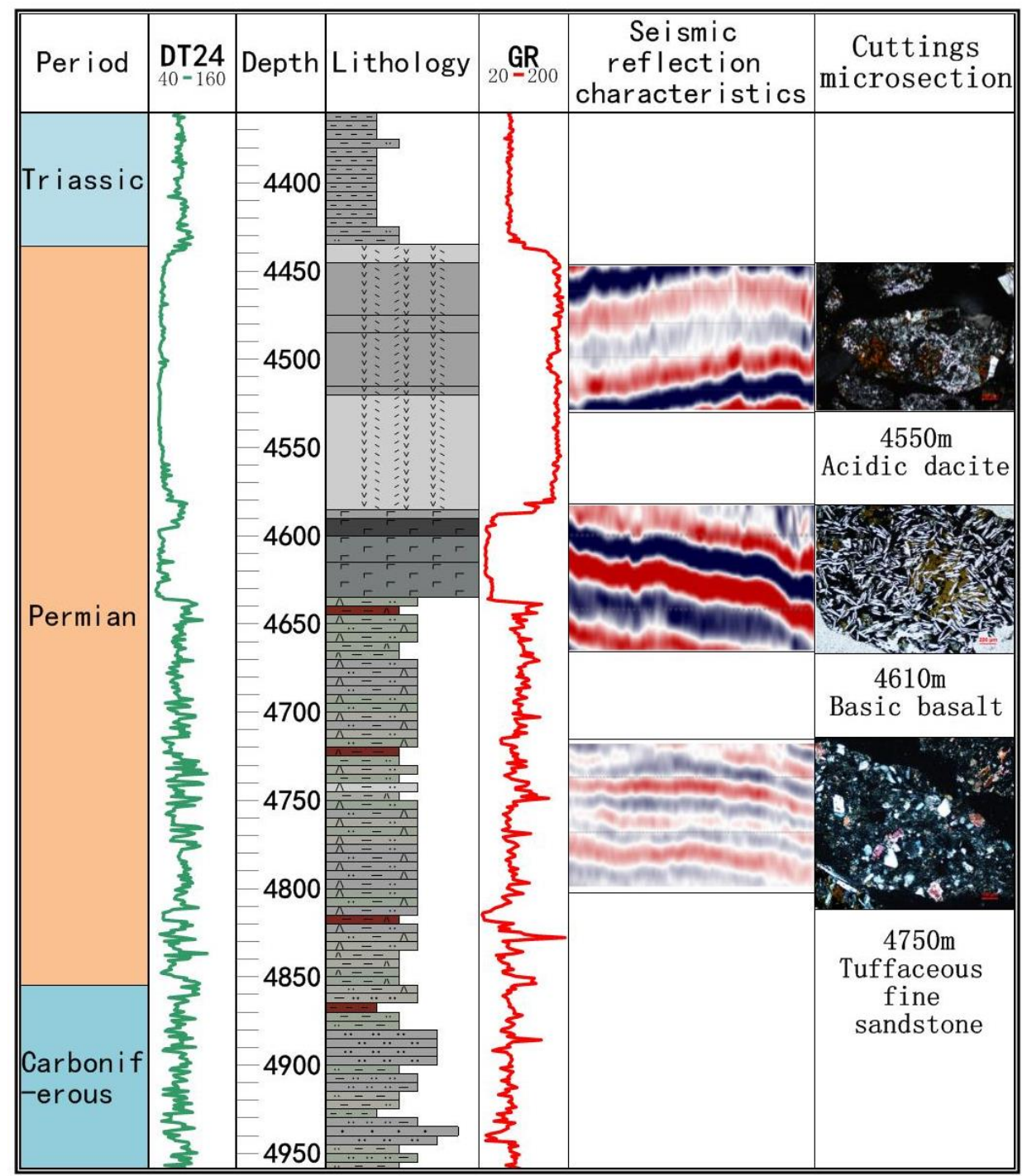

Fig. 5 Comprehensive strata log diagram of FY201 well

Integrating logging, seismic and analysis of cuttings microsection, the general lithology distribution pattern of Permian igneous in FY area has been obtained: the igneous lithology in the upper Permian are dominated by dacite and the middle part is dominated by basalt, while the lower part is pyroclastic rocks with complex lithology which is dominated by tuff and tuffaceous sandstone and mudstone. However, the thickness of igneous rock with complex lithology in FY area is large. If there are other lithologies in each igneous lithology segment, fine lithologic inversion is needed to identify them.

\section{2. Analysis of the effect of geostatistical lithologic inversion}

Through the geostatistical inversion of the Permian igneous rocks in the FY study area, 10 types of igneous probabilities are obtained by 10 sorts of realizations, due to the large work area and large amount of calculation. Fig. 6 shows the geostatistical inversion section of crosswell FY201, FY203 and FY204. Compared with Fig. 1, the rock shape and the scale of 
distribution of the two wave impedance profiles are roughly the same. Moreover, the wave impedance around the wells in the igneous geological inversion section match with the wave impedance obtained well logging data, which verifies that the geostatistical inversion can correctly reflect the igneous lithological and physical distribution characteristics of FY area.

In lithologic resolution, the constrained sparse spike inversion in Fig. 1 roughly depicts the changes in lithology, and details of the information are not rich enough. In Fig. 6, it can be seen that some of the thin layers of low-velocity lithologic bodies are identified in the upper part of the Permian, and in the pyroclastic rocks formation, the lower part of the Permian, several sets of high-velocity igneous rock have been identified. The longitudinal resolution has been greatly improved.

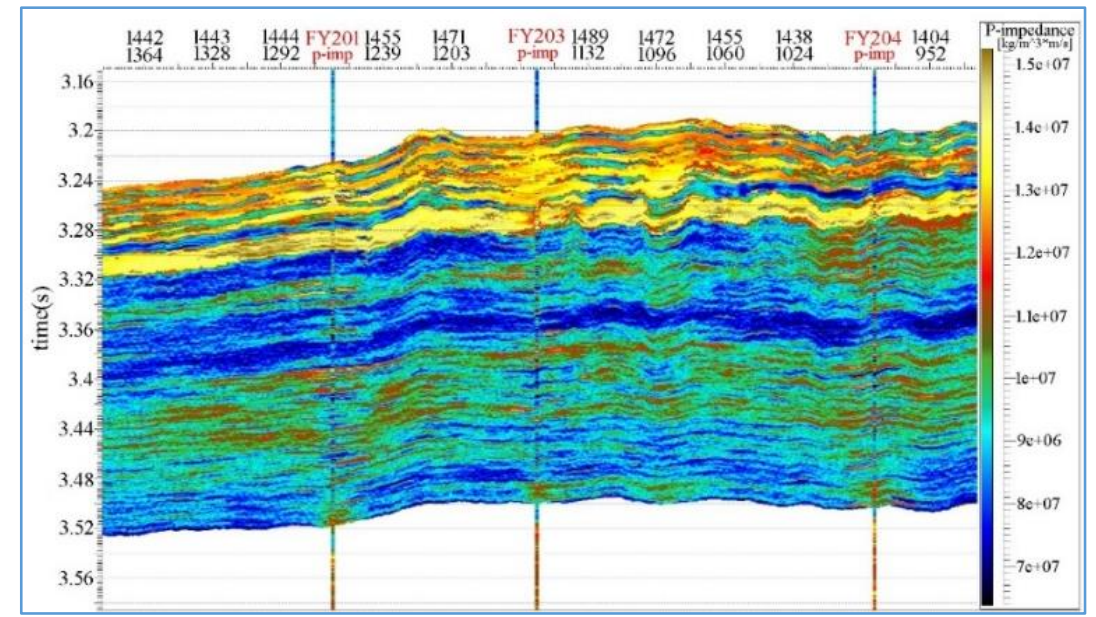

Fig. 6The geostatistical inversion section of cross-well FY201, FY203 and FY204

Drilling proved that FY1 wells drilled two sets of basic basalts, which are easy to distinguish, due to its lower natural gamma value between 30-50 GAPI. The continuity of phase axis is good. Fig. 7 is the cross FY1 well section of basalt identification to compare the detail recognition ability between constrained sparse pulse inversion and geostatistical inversion method. It can be seen that the basalt's contour identified by geostatistical inversion is more clear and more natural. In summary, the geostatistical inversion identifies the igneous rock with high accuracy and resolution, and the effect is good. 


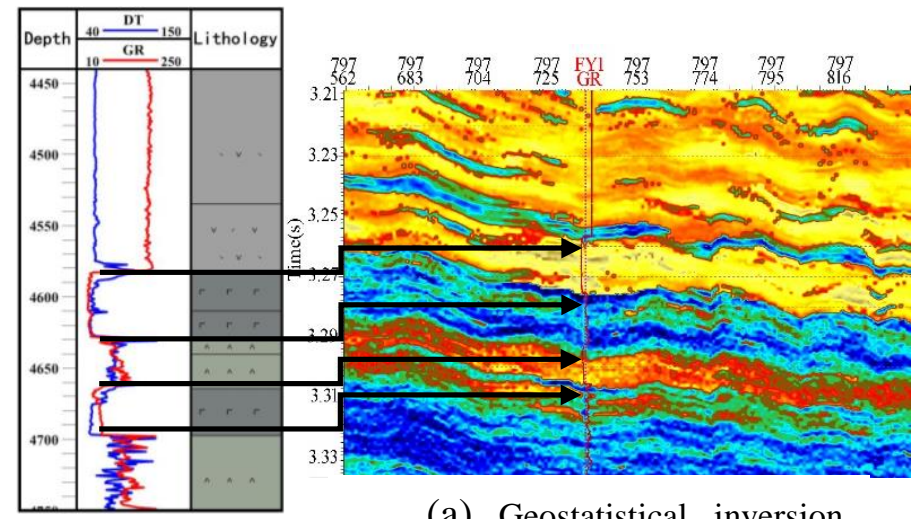

(a) Geostatistical inversion

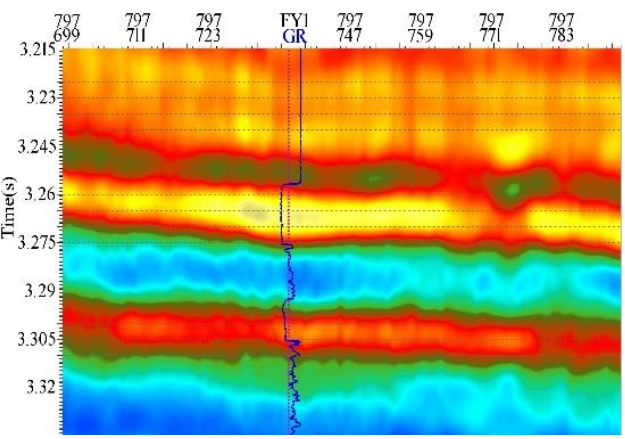

(b) Constrained sparse pulse inversion

Fig. 7 Comparative analysis of inversion section of cross-well FY1

\section{3. Lithologic distribution analysis of Permian igneous in FY area}

10 kinds of igneous rock lithology probabilities were acquired by geostatistical inversion, and the probability bodies of the three lithologies were obtained, namely, dacite probability body, basalt probability body and pyroclastic rocks probability body. Fig. 8 shows the three lithologies' probability profiles of cross-well FY201, FY203, FY204 and FY202, and the color in the profiles is the probability value of a certain lithology. From Fig. 8 (a), it can be known that the dacite are mainly located in the upper part of the Permian, where several sets of relatively continuous "other lithologic body" are also located in. While the probability of the dacite in the lower part of the Permian is below 10\%。Fig. 8 (b) shows the basalt probability profile. The temperature of the basaltic magma is high, usually above $1100{ }^{\circ} \mathrm{C}$. The viscosity is low and the bursting ability is weak. Therefore, combined with the seismic and geological data, the relatively continuous high probability strata in the upper parts of Fig. 8 (b) can be predicted as basalt. And the upper and lower intermittent high probability rock bodies are considered as false information, not basalt. It can be seen from Fig. 8 (c) that the stratum lithology under the basalt in the Permian is dominated by pyroclastic rocks, and there are three to four sets of pyroclastic rocks in the upper Permian. It can be concluded that the "other lithologic body" in Fig. 8 (a) are pyroclastic rocks.

Comprehensive Fig. 8 and Fig. 6, and the lithologic distribution in the general geology, the igneous lithologic distribution pattern of Halahatang FY area in Permian can be further updated. The main lithology of upper Permian is dacite, of which there are three to four sets of pyroclastic rocks. There is a relatively continuous pyroclastic rocks interlayer between dacite and basalt, and the stratum lithology under the basalt is dominated by pyroclastic rocks. 


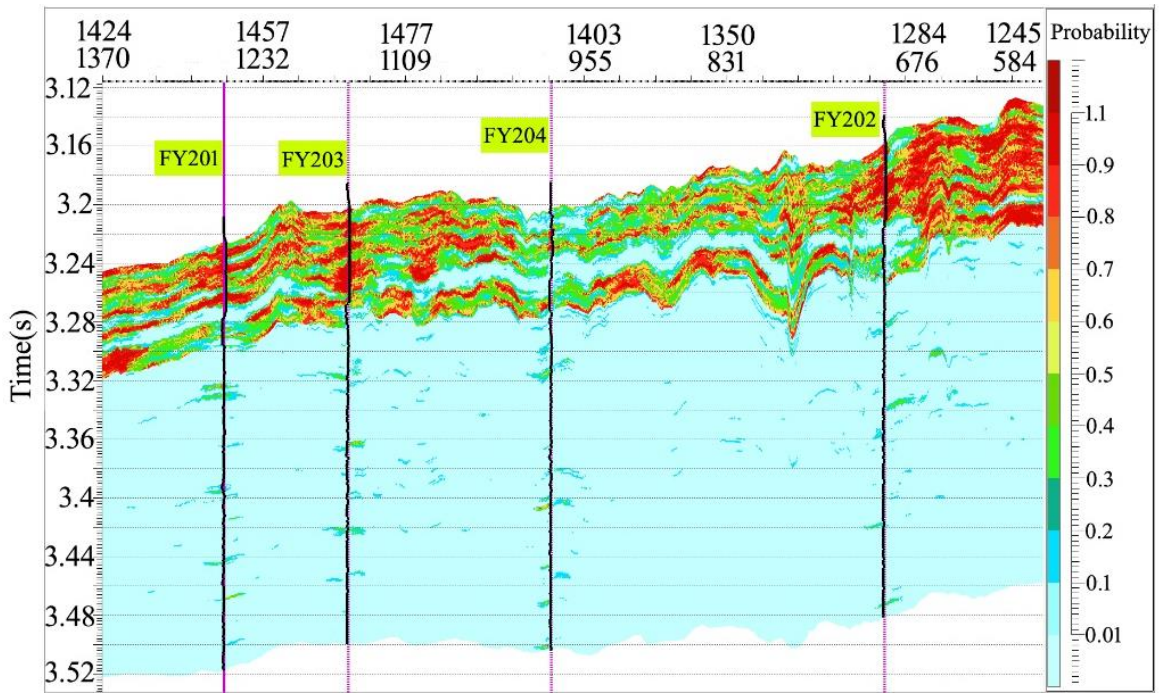

(a) Dacite probability body

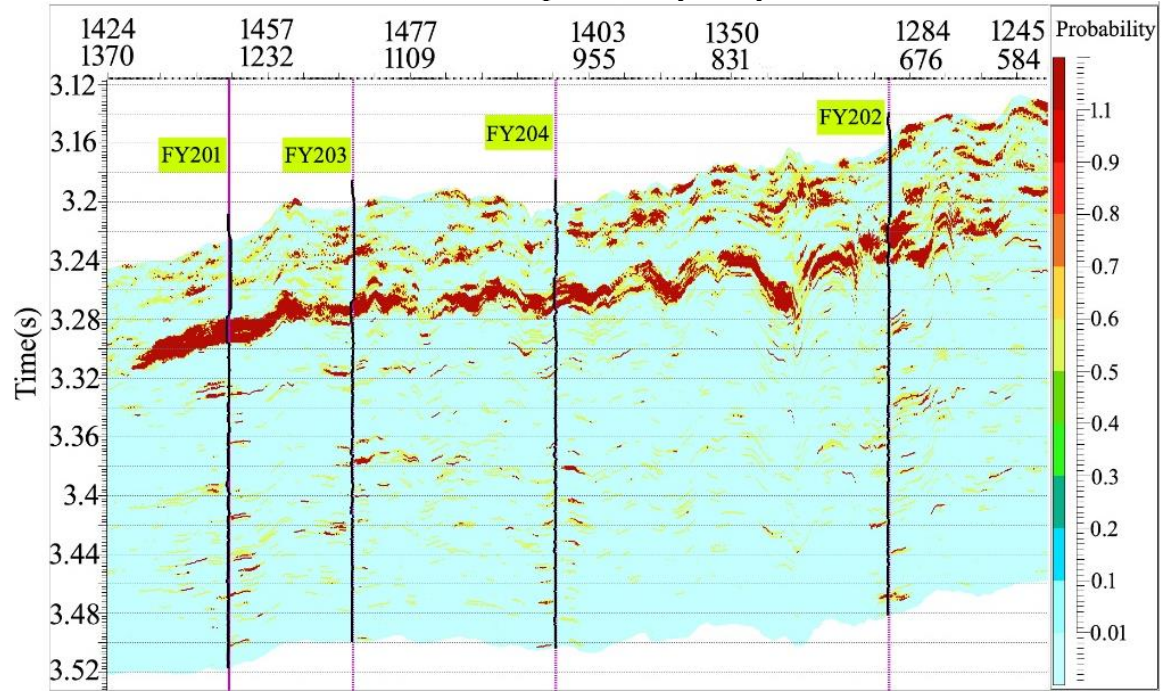

(b) Basalt probability body

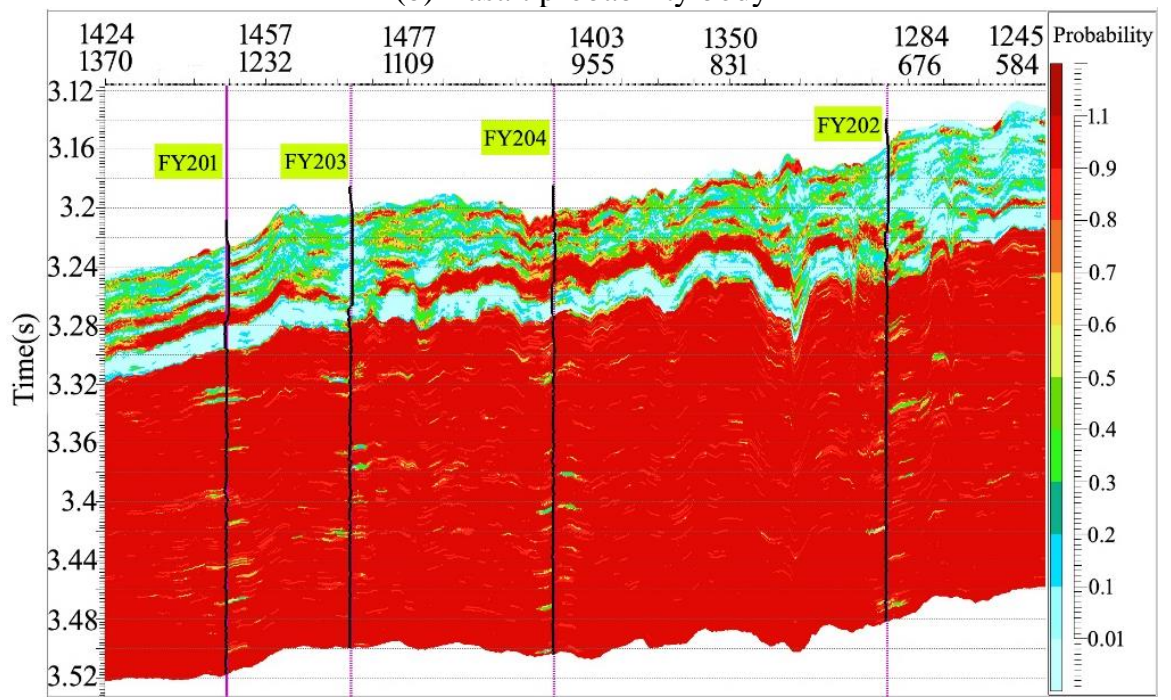

(c) Pyroclastic rocks probability body

Fig. 8The three lithologies' probability profiles of cross-well FY201, FY203, FY204 and FY202 


\section{4. Analysis of the effect of velocity modeling in Geostatistical inversion}

The high-resolution igneous impedance obtained by geostatistical inversion is transformed into igneous velocity by empirical transformation formula which is obtained by fitting the velocity and density data in the region. It can better reflect the characteristics of the igneous. After the transformation, the lithology resolution of igneous is keep unchanged. Thus, the highprecision velocity model of the Permian igneous based on geostatistical inversion in the FY area is obtained. In order to reflect the accuracy of the velocity model and the ability to distinguish the igneous rock, the pseudo-velocity curves of the FY201, FY203 and FY204 wells are extracted. At the same time, we also extract the pseudo-velocity curve of the CSSI velocity and compare them with the original velocity curve to analyze the effect of velocity modeling. The comparison of the three velocity curves is shown in Fig. 9. The cyan curve is the original velocity obtained by the well logging; The blue curve is the pseudo-well velocity extracted by the CSSI velocity model; The red curve is the pseudo-well velocity extracted by the highprecision velocity body obtained by the geostatistical inversion.

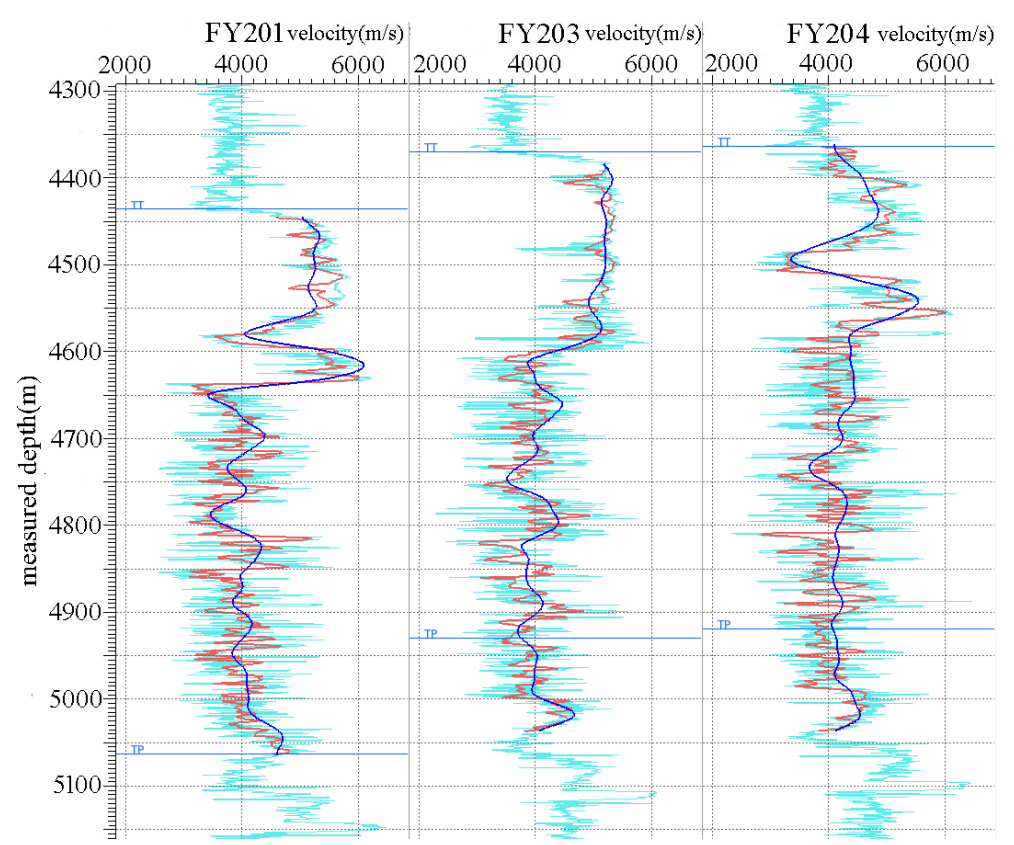

Fig. 9 Comparison of pseudo-velocity curves of different inversion methods in well FY201, FY203 and

FY204

It can be seen from Fig. 9 that the velocity curve obtained by CSSI is relatively smooth and can reflect the velocity trend in the longitudinal direction of the igneous, but the velocity detail information is not enough. The velocity curve obtained from geostatistical inversion is in good agreement with the original velocity curve of the wells and have high lithological resolution ability. The details of the velocity variation are also rich which can reflect the velocity information of the underground strata more realistically. 
In order to quantitatively analyze the precision of inversion velocity, the CSSI velocity and geostatistical inversion velocity of YM4, FY102, FY104, FY201, FY203, FY204 and other well points are extracted and the YM4 well is the verification well and is not involved in the inversion. The average velocity of the Permian in each well is obtained and compared with the original average velocity of each well. Then the velocity error under two inversion methods is calculated, which is illustrated in Table 2 . It can be seen that the velocity model obtained by the geostatistical inversion is maintained at good lithologic resolution, and the velocity accuracy is also high. The error is controlled within $2 \%$. Therefore, compared with the commonly used velocity modeling method, geostatistical inversion velocity modeling has a high precision and superior lithologic resolution.

Table 2 Comparison of velocity errors between two inversion methods

\begin{tabular}{|c|c|c|c|c|c|c|c|c|}
\hline \multicolumn{2}{|c|}{ Inversion velocity analysis } & \multirow{2}{*}{$\begin{array}{l}\text { YM4 } \\
4368.6\end{array}$} & \multirow{2}{*}{$\begin{array}{l}\text { FY102 } \\
4376.3\end{array}$} & \multirow{2}{*}{$\begin{array}{l}\text { FY104 } \\
4359.7\end{array}$} & \multirow{2}{*}{$\begin{array}{l}\text { FY201 } \\
4359.7\end{array}$} & \multirow{2}{*}{$\begin{array}{l}\text { FY203 } \\
4319.9\end{array}$} & \multirow{2}{*}{$\begin{array}{l}\text { FY204 } \\
4305.4\end{array}$} & \multirow{2}{*}{$\begin{array}{l}\text { Mean } \\
4348.3\end{array}$} \\
\hline $\begin{array}{ll}\text { Original velocity } \\
\text { from well }\end{array}$ & $\begin{array}{l}\text { Value } \\
(\mathrm{m} / \mathrm{s})\end{array}$ & & & & & & & \\
\hline \multirow{2}{*}{$\begin{array}{l}\text { Velocity } \\
\text { CSSI }\end{array}$} & $\begin{array}{l}\text { Value } \\
(\mathrm{m} / \mathrm{s})\end{array}$ & 4342.7 & 4370.9 & 4304.2 & 4304.1 & 4314.6 & 4283.4 & 4319.9 \\
\hline & Error & $-0.59 \%$ & $-0.12 \%$ & $-1.27 \%$ & $1.04 \%$ & $-0.12 \%$ & $-0.51 \%$ & $-0.26 \%$ \\
\hline \multirow{2}{*}{$\begin{array}{l}\text { Velocity } \\
\text { geostatistical } \\
\text { inversion }\end{array}$} & $\begin{array}{l}\text { Value } \\
(\mathrm{m} / \mathrm{s})\end{array}$ & 4401.6 & 4386.2 & 4285.3 & 4344.1 & 4342.6 & 4290.1 & 4341.7 \\
\hline & Error & $0.75 \%$ & $0.23 \%$ & $-1.71 \%$ & $1.98 \%$ & $0.53 \%$ & $-0.36 \%$ & $0.23 \%$ \\
\hline
\end{tabular}

After comparing the numerical accuracy, the high-precision igneous velocity model based on geostatistical inversion and the conventional strata-bound velocity model are applied to the seismic data processing, and Fig. 10 shows the comparation of the migration results. The Fig. 10(a) figure shows the offset profile obtained by using the conventional strata-bound velocity model to process the seismic data, and the Fig. 10 (b) figure shows the offset profile obtained by using the high-precision velocity model in this study. Comparing the two profiles, the internal description of igneous rocks is clearer in the profile of the Fig. 10 (b). The signal-tonoise ratio is improved, and the continuity is enhanced. Therefore, in addition to reservoir prediction, geostatistical inversion can be used as an effective method to establish the fine velocity model of igneous rock or other lithology and can provide high precision velocity model for seismic data processing. 


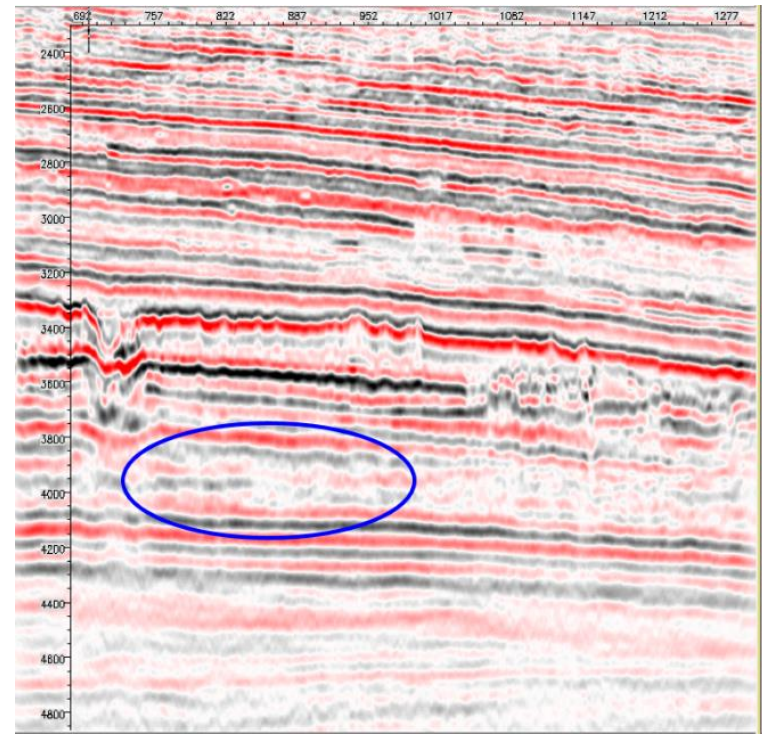

(a) the conventional strata-bound velocity model

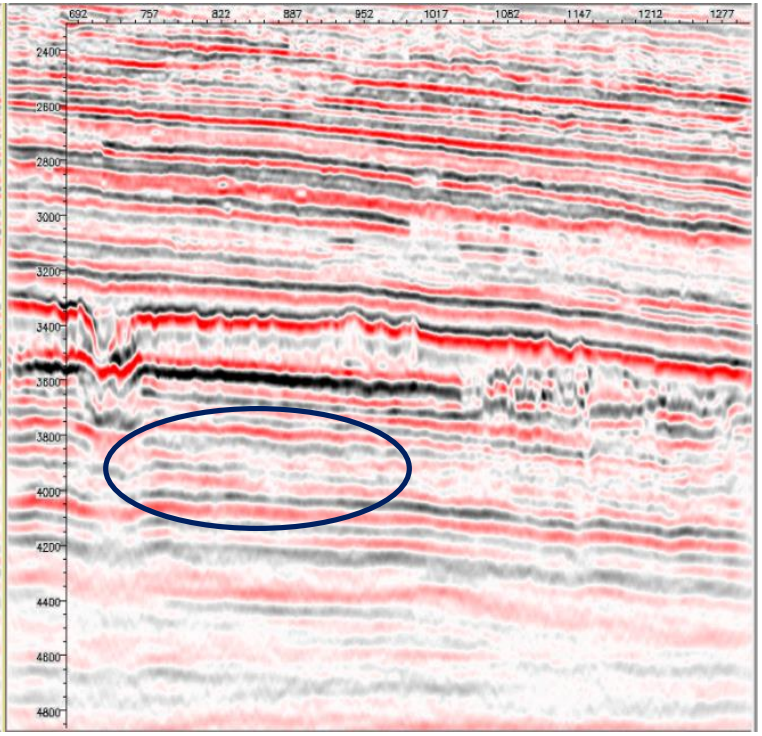

(b) geostatistical inversion velocity model.

Fig. 10 Comparison of offset imaging using different velocity models

\section{Conclusions}

In the study, a geostatistical inversion method is applied to lithology identification and velocity modeling of the Permian thick igneous rock in the FY area of northern Tarim Basin. The following conclusions are achieved:

(1) CSSI respects seismic data and can roughly reflect the distribution characteristics of lithology. On this basis, the geostatistical inversion is used to identify the igneous lithology, which depicts the shape and contour of the igneous more clearly. By analyzing the wave impedance and the probability body of different igneous lithology, a more accurate distribution pattern of Permian igneous in FY area is obtained. That is, the igneous lithology in the upper Permian are dominated by dacite, of which there are three to four sets of pyroclastic rocks. The main igneous lithology of middle Permian is basalt, while the igneous lithology of lower Permain is pyroclastic rocks with complex lithology which is dominated by tuff and tuffaceous sandstone and mudstone. In addiation, there is a relatively continuous pyroclastic rocks interlayer between dacite and basalt.

(2) Velocity model obtained by geostatistical inversion can reflect the details of the velocity variation of the Permian igneous rock.The drilling results verified the high accuracy of the geostatistical inversion velocity modeling. The velocity error of well point is controlled within $2 \%$ and the average error is $0.23 \%$. It can provide high precision igneous velocity model for formation pressure prediction and seismic data processing. It also provides a reliable basis for variable velocity mapping and trap ascertainment, and ultimately guide the work of oil exploration and development. 
(3) Lithological information obtained by geostatistical inversion is rich and the resolution is high, but the calculation of inversion is large and the statistical work is also more complex. In addition, the inversion work is more suitable for areas that has more drilling wells. In contrast, other modeling methods such as CSSI and tomographic inversion are more suitable for largescale and fast velocity modeling.

\section{Acknowledgements}

This work was supported by the project funded by the Priority Academic Program Development of Jiangsu Higher Education Institutions, by the China Postdoctoral Science Foundation (Grant No. 2014M551703, 2018M630631), and by the Fundamental Research Funds for the Central Universities (Grant No. 2012QNA62, 2018QNB12).

\section{References}

Bellatreche, K.-E., Couch, A. and Evans, R., 2017. Detailed seismic lithofluid distribution using Bayesian stochastic inversion for a thinly bedded reservoir: A case study over Huntington UK Central North Sea. Interpretation, 5(3): SL25-SL32.

Cui, Y., Xu, Y. and Peng, G., 2016. Igneous rock identification and velocity modeling based on several seismic inversion methods in Halahatang area. Journal of Northeast Petroleum University, 40(4): 54 -62.

Dong, Q., Lu, S., Zhang, X. and Shang, J., 2013. election of parameters and reliability analysis of results in geostatistical inversion method. Geophysical \& Geochemical Exploration, 37(2): 328-332.

Goovaerts, P., 1994. Comparative performance of indicator algorithms for modeling conditional probability distribution functions. Mathematical Geology, 26(3): 389-411.

Han, D. et al.

He, J., 2013. A high resolution method for fluid prediction based on geostatistical inversion. International Journal of Geophysics, 2013.

Luo, F., 2006. Study on Characteristic and Predicting Technology of Igneous rocks in Tazhon Area of Tarim Basin, China University of Geosciences (Beijing).

Naviset, S., Morley, C.K., Naghadeh, D.H. and Ghosh, J., 2017. Sill emplacement during rifting and inversion from three-dimensional seismic and well data, Phitsanulok Basin, Thailand. Geosphere, 13(6): 2017-2040.

Pereira, Â., Nunes, R., Azevedo, L., Guerreiro, L. and Soares, A., 2017. Geostatistical seismic inversion for frontier exploration. Interpretation, 5(4): T477-T485.

Sabeti, H. et al., 2017. Geostatistical seismic inversion for non - stationary patterns using direct sequential simulation and co - simulation. Geophysical Prospecting, 65: 25-48.

Sammarco, C., Cornwell, D.G. and Rawlinson, N., 2017. Ambient noise tomography reveals basalt and sub-basalt velocity structure beneath the Faroe Islands, North Atlantic. Tectonophysics, 721: 1-11.

Shen, H., Qin, D. and Hou, D., 2016. Predication of super thin reservoir based on geostatistical inversion, SEG Technical Program Expanded Abstracts 2016. Society of Exploration Geophysicists, pp. 2891-2895.

Tamaki, M., Suzuki, K., Fujii, T. and Sato, A., 2016. Prediction and validation of gas hydrate saturation distribution in the eastern Nankai Trough, Japan: Geostatistical approach integrating well-log and 3D seismic data. Interpretation, 4(1): SA83-SA94. 
Wang, Y. and Wang, L., 2013. Application of geostatistical inversion to reservoir prediction in the Western Slope of the northern Xingshugang oil field. Progress in Geophysics, 28(5): 2554-2560.

Xie, H., Xu, Y. and Zheng, D., 2015 Multi-attribute probabilistic neural network inversion applicated in identifying igneous in RWP area based on cross-validation. China Mining Magazine(2): 154-158.

Yang, H. et al., 2011. Comparison between several multi-parameter seismic inversion methods in identifying plutonic igneous rocks. Mining Science and Technology (China), 21(3): 325-331.

Yongzhong, X., Tongjun, C., Shizhong, C., Huang, W. and Gang, W., 2010. Comparison between several seismic inversion methods and their application in mountainous coal fields of western China. Mining Science and Technology (China), 20(4): 585-590.

Zhang, J., Liu, L. and Wang, R., 2017. Geostatistical Three-Dimensional Modeling of a Tight Gas Reservoir: A Case Study of Block S6 of the Sulige Gas Field, Ordos Basin, China. Energies, 10(9): 1439.

Zhang, S., Liu, T. and Gu, H., 2003. Identification of Igneous Rocks by Artificial Neural Network. Oil Geophysical Prospecting, 38: 84-87.

Zhang, Z., Cao, D. and Yin, X., 2016. Research and application status of well seismic joint velocity modeling in time-depth conversion. Progress in Geophysics, 31(5): 2276-2284.

Zhi, G., Longde, S., Ailin, J. and Tao, L., 2015. 3-D geological modeling for tight sand gas reservoir of braided river facies. Petroleum Exploration and Development, 42(1): 8391. 